\title{
Differential Effects of Antidepressants on Glucocorticoid Receptors in Human Primary Blood Cells and Human Monocytic U-937 Cells
}

\author{
Andreas Heiske*,', Jutta Jesberg', Jürgen-Christian Krieg' and Helmut Vedder' \\ 'Department of Psychiatry and Psychotherapy, Philipps-University, Marburg, Germany
}

\begin{abstract}
A number of data support the assumption that antidepressants (ADs) normalize the altered function of the hypothalamic-pituitaryadrenocortical (HPA) system involved in the pathophysiology of depressive disorder via direct effects on glucocorticoid receptors (GRs). In the present study, we examined the tricyclic ADs desipramine (DESI) and imipramine (IMI), the noradrenaline reuptake inhibitor maprotiline (MAPRO), and the noradrenergic and specific serotonergic AD (NaSSA) mirtazapine (MIR) for their effects on GR expression in primary human leukocytes and in monocytic U-937 cells. Semiquantitative RT-PCR indicated that the ADs exert differential effects on GR-mRNA levels in both primary human leukocytes and U-937 cells: whereas MAPRO and IMI did not induce pronounced changes in GR-mRNA levels, DESI and MIR significantly decreased the amounts of GR-mRNA in both cell systems. Further characterization of the effects of MIR revealed a time dependency of the regulation with an initial increase of GR-mRNA levels above control levels after $2.5 \mathrm{~h}$ of treatment and a decrease after 4, 24, and $48 \mathrm{~h}$ of incubation. A dose-response analysis demonstrated maximal effects of MIR at a concentration of $10^{-7} \mathrm{M}$. Immunohistochemical studies showed that MIR increased the GR protein levels in a timedependent manner and that this upregulation appeared earlier by additional treatment with dexamethasone (DEX). A translocation of the GR protein from the cytoplasm to the nucleus was induced between 24 and $48 \mathrm{~h}$ of treatment with MIR and MIR/DEX, respectively. Taken together, our data further support the assumption that ADs influence the neuroendocrine and immune system via effects on cellular GRs.

Neuropsychopharmacology (2003) 28, 807-8I7. doi:10.1038/sj.npp. 1300056
\end{abstract}

Keywords: depressive disorder; monocytes; glucocorticoid receptor; antidepressants; dexamethasone

\section{INTRODUCTION}

Research of the last years fostered the hypothesis that glucocorticoid receptor (GR) dysfunctions are critically involved in the hyperactivity of the hypothalamic-pituitary-adrenocortical (HPA) system present in major depressive disorder (MDD) (Arborelius et al, 1999; Holsboer, 2000; Pariante and Miller, 2001). Moreover, it has been shown that the level of the HPA activity in depressive patients is crucially related to the psychopathological course of the disease (Ribeiro et al, 1993; Holsboer, 1995; Zobel et al, 1999).

Therefore, the effects of antidepressants (ADs) on GRs, the HPA system and its functions are of increasing interest

\footnotetext{
*Correspondence: Dr Andreas Heiske, Department of Virology, Philipps-University of Marburg, Robert Koch Strasse 17, D-35037 Marburg, Germany, Fax: 004964212865 482,

E-mail: Heiske@mailer.uni-marburg.de

Received 26 April 2002; revised 29 August 2002; accepted 3 September 2002

Online publication: 9 June 2002 at http://www.acnp.org/citations/ Npp090602376
}

with regard to their therapeutic mechanism of action. For example, recent research demonstrated that various $\mathrm{ADs}$ inhibit the corticosterone-induced gene transcription in a concentration- and time-dependent manner in fibroblast cells (Budziszewska et al, 2000). Moreover, long-term treatment of rats with the ADs desipramine (DESI) and amitriptyline (AMI) was found to upregulate hippocampal GR-mRNA levels (Barden et al, 1995; Okugawa et al, 1999).

The majority of studies using tricyclic ADs, such as DESI, AMI, and imipramine (IMI) indicated an AD-induced GRupregulation in the brain (Pepin et al, 1992; Seckl and Fink, 1992; Reul et al, 1993; Przegalinski and Budziszewska, 1993; Budziszewska et al, 1994; Pariante and Miller, 2001), whereas only a few studies showed a downregulation of GR in the brain (Brady et al, 1991; Biagini et al, 1993; Peeters et al, 1994; Pariante and Miller, 2001).

In addition to the well-known neuropharmacological actions of $\mathrm{ADs}$ and their effects on the neuroendocrine system via GRs, studies have elucidated that the effects of ADs on immune functions may play an important role in the treatment of MDD (Maes et al, 1995; Rothermundt et al, 2001). Interestingly, functional experiments showed an 
increased resistance of immune cells from depressed patients to the inhibitory effects of glucocorticoids (Pariante et al, 1995). Therefore, the neuroendocrine and the immunological data support the hypothesis that the effects of ADs on the properties of GRs and on the GR-induced intracellular signal transduction may represent one of their most important modes of action (Barden et al, 1995; Pariante et al, 1995; Pariante and Miller, 2001).

Until now, the effects of ADs on the GR have mainly been characterized in in vitro systems and in rodents (Pepin et al, 1989, 1992; Reul et al, 1994; Pariante and Miller, 2001). Therefore, the transfer of the knowledge to the human system is as yet rather limited. Recent data from our group show that ADs are indeed able to upregulate GR-mRNA levels in human peripheral blood cells (Vedder et al, 1999), suggesting that such cells may serve as a model system for the study of the effects of ADs on GRs in general.

To further clarify this type of actions in a human system, we here examined the classical ADs DESI, IMI, maprotiline (MAPRO), and the new-class AD mirtazapine (MIR) for their effects on GR-mRNA levels in human primary blood cells of male volunteers and in human monocytic U-937 cells. The distinct pharmacological profile of the AD MIR was the reason for a more detailed characterization of the time- and dose-dependence of its effects on the GR-mRNA in undifferentiated and differentiated human monocytic U-937 cells, respectively. Besides the effects of ADs on the mRNA levels, we investigated GR expression and translocation- important processes involved in the cellular actions of the GR - after MIR and simultaneous treatment with MIR and dexamethasone (DEX) with an immunostaining procedure.

\section{METHODS}

\section{Blood Cell Preparations}

A total of 11 healthy subjects were screened by a psychiatrist to assure the absence of physical diseases, a history of psychiatric disorders, and the use of any medication. Citrate blood was obtained by venipuncture in the morning between 8.00 and 9.00 am and incubated for $24 \mathrm{~h}$ at $37^{\circ} \mathrm{C}$ on a rotatory roller with $10^{-7} \mathrm{M}$ of ADs (DESI, IMI, MAPRO, MIR) dissolved in ethanol and the respective controls with $10^{-5} \mathrm{M}$ ethanol. After the incubation, whole blood samples were collected and erythrocytes lysed with $0.8 \%$ ammonium chloride. At the end of the lysis, the cell pellets were exposed to $1 \mathrm{ml}$ of Trizol ${ }^{\circledR}$ reagent (GibcoBRL, Karlsruhe, Germany) and frozen at $-20^{\circ} \mathrm{C}$.

\section{U-937 Cells and Culture Conditions}

U-937 cells were maintained in Roswell Park Memorial Institute (RPMI) 1640 medium supplemented with 10\% heatinactivated fetal calf serum (FCS) (Gibco/BRL and Seromed, Berlin, Germany), 0.5\% glutamine, and 1\% gentamycine at $37^{\circ} \mathrm{C}$ in a $5 \% \mathrm{CO}_{2}$ atmosphere. For further studies, cells were plated at a concentration of $3 \times 10^{5}$ cells $/ \mathrm{ml}$ in six-well culture plates (Greiner, Frickenhausen, Germany) and treated with DESI, IMI, MAPRO, and MIR dissolved in ethanol as well as with ethanol-controls (ETH/CON).

ADs were purchased from Sigma-Aldrich (Deisenhofen, Germany); MIR was a kind gift of Organon, Munich,
Germany. The stock concentrations of the ADs in ethanol $\left(10^{-2} \mathrm{M}\right)$ were diluted to the final concentrations of $10^{-7} \mathrm{M}$, and the final concentration of ethanol was $10^{-5} \mathrm{M}$ in the treatment samples.

U-937 cells were grown in medium under basal conditions and differentiated to monocytes by treatment with $10 \mathrm{nM}$ phorbol 12-myristate 13-acetate (PMA) (Sigma-Aldrich, Germany) in medium for 3 days. For further studies on the mechanisms of the $\mathrm{AD}$ effects, cells were exposed simultaneously to the RNA synthesis inhibitor Actinomycin $\mathrm{D}$ (Sigma-Aldrich, Germany) and the ADs $\left(10^{-7} \mathrm{M}\right)$ for $24 \mathrm{~h}$. At the end of the incubation period, the cells were collected and frozen at $-20^{\circ} \mathrm{C}$.

\section{RNA Extraction}

RNA was extracted from the blood cells and the U-937 cells using Trizol ${ }^{\circledR}$ reagent in accordance with the manufacturer's instructions. The amount of extracted total RNA was quantified by established optical methods at $\mathrm{A}_{260} / \mathrm{A}_{280}$ (Genequant II, Pharmacia Biotech, Freiburg, Germany) and the structural integrity checked by agarose gel electrophoresis (1.0\% agarose (Gibco/BRL)).

\section{Reverse Transcriptase-Polymerase Chain Reaction (RT-PCR)}

RT-PCR was used to analyze the transcription of the GRand the house-keeping gene glyceraldehyde-3-phosphate dehydrogenase (GAPDH)-mRNA. Total RNA of $1 \mu \mathrm{g}$ was reverse-transcribed and amplified with the $\operatorname{Titan}^{\mathrm{TM}}$ One Tube RT-PCR System (Boehringer, Mannheim, Germany) or reverse-transcribed with $40 \mathrm{U}$ of Superscript II (Gibco/BRL) and $1 \mu \mathrm{g}$ oligo-(dT) in a total volume of $20 \mu \mathrm{l}$ following the manufacturer's protocol.

The following primer pairs were used to amplify the cDNA's:

hGR (5'primer: $5^{\prime}$-TGG TGT CAC TGT TGG AGG TTA-3'; 3'primer: $5^{\prime}$-GGC TCT TCA GAC CGT CCT T-3') (453 bp);

GAPDH (5' primer: $5^{\prime}$-CGT CTT CAC CAC CAT GGA GA-3'; 3'primer: $5^{\prime}$-CGG CCA TCA CGC CAC AGT TT-3') (300 bp).

Aliquots of $1 \mu \mathrm{l}$ cDNA were amplified with a PCR cycler (Biometra Trio, Göttingen, Germany) for GR and GAPDH using the primers described above with the following cycling program: denaturation for $45 \mathrm{~s}$ at $95^{\circ} \mathrm{C}$, annealing for $60 \mathrm{~s}$ at $59^{\circ} \mathrm{C}$, and extension for $60 \mathrm{~s}$ at $72^{\circ} \mathrm{C}$. PCR products were analyzed for GR (28 cycles) and GAPDH (28 cycles) after amplification and gel electrophoresis in $1 \%$ agarose gels. Semiquantitative determination was achieved by digitization of gels with a Polaroid video system (Rothaar \& Schroeder, Heidelberg, Germany) and further densitometric evaluation with the Gelscan 4.0 Professional Program (LTF/BioSciTec, Landau/Frankfurt, Germany).

\section{DNA Sequence Analysis}

For sequencing, PCR amplification products were gelpurified (QIAGEN, QIAquick Gel Extraction Kit; Qiagen, Hilden, Germany). Direct sequencing of PCR products was performed by cycle sequencing in both directions with $\mathrm{ABI}$ PRISM Big Dye Terminator chemistry (Perkin-Elmer, Weiterstadt, Germany) followed by electrophoresis on a 
Perkin-Elmer ABI-377 automated sequencer. The amplified GR sequence and the gene-bank information on the GR revealed an identity of $100 \%$ of both sequences.

\section{GR Immunofluorescence Detection}

For the immunofluorescence experiments, differentiated U937 cells were cultured in Dulbecco's modified Eagle's medium (DMEM) (Gibco/BRL) supplemented with 10\% heat-inactivated FCS, $2 \mathrm{mM}$ glutamine, and $50 \mathrm{U} / \mathrm{ml}$ penicillin and $50 \mu \mathrm{g} / \mathrm{ml}$ streptomycin at $37^{\circ} \mathrm{C}$ in a $5 \% \mathrm{CO}_{2}$ atmosphere. For further studies, cells were plated and grown in DMEM supplemented with $1 \%$ FCS at a concentration of $3 \times 10^{5}$ cells $/ \mathrm{ml}$ in six-well culture plates (Greiner, Frickenhausen, Germany) and exposed to $10^{-6} \mathrm{M}$ of MIR alone and simultaneously with $10^{-6} \mathrm{M}$ DEX for 1 , $2.5,4,24$, and $48 \mathrm{~h}$. At the end of the incubation period, cells were washed with phosphate-buffered saline (PBS) pH 7.4. Afterwards, cells were permeabilized and fixed with acetone/methanol $(1: 1)$ for $15-30 \mathrm{~min}$ at $4^{\circ} \mathrm{C}$. The fixed cells were washed 4 times with PBS and visualization of intracellular GR expression was carried out by indirect immunofluorescence employing a mouse anti-human GR antibody (H-300) $(1: 1000)$ at incubation conditions of $120 \mathrm{~min}$ and $4^{\circ} \mathrm{C}$ (Santa Cruz Biotechnology, Heidelberg, Germany), and a secondary fluorescein isothiocyanate (FITC) labeled rabbit anti-mouse IgG antibody $(1: 500)$ for $60 \mathrm{~min}$ at $4^{\circ} \mathrm{C}$ (Dako A/S, Hamburg, Germany). After antibody incubation, the fixed cells were washed 4 times with PBS. For documentation, the photographic equipment of an Axiophot microscope (Zeiss, Jena, Germany), a Spot 32 camera, and a documentation program (Diagnostic
Instruments Zeiss) was used. The quantitative analysis of fluorescence was performed in blindly selected regions from the cytoplasm and the nucleus by densitometric evaluation with the Gelscan 4.0 Professional Program.

\section{Statistical Analysis}

Data of different experiments were adjusted with regard to the mean of the respective control group and are presented as mean \pm SEM. If a homogeneity of variances and a normal distribution of data was detectable, one-way analysis of variance and appropriate post hoc tests (Student-Newman-Keuls tests) were used for statistical analysis. Values were considered as significant with a $p \leqslant 0.05\left({ }^{*} p \leqslant 0.05,{ }^{*} p \leqslant 0.01\right)$. If data lacked a homogeneity of variances and/or a normal distribution, they were analyzed with the Kruskal-Wallis one-way analysis of variance on ranks. When this test revealed a significance of the treatment condition, Mann-Whitney rank sum tests were used for between-group comparisons.

\section{RESULTS}

\section{Effects of ADs on GR-mRNA Levels in Human Peripheral Blood Cells}

One aim of the study was to determine the differential effects of several types of ADs on GR-mRNA transcription in primary human blood cells. After a $24 \mathrm{~h}$ treatment, the ADs DESI, IMI, MAPRO, and MIR exerted differential effects on GR-mRNA levels (Figure 1). Semiquantitative evaluation of PCR data indicated that a concentration of
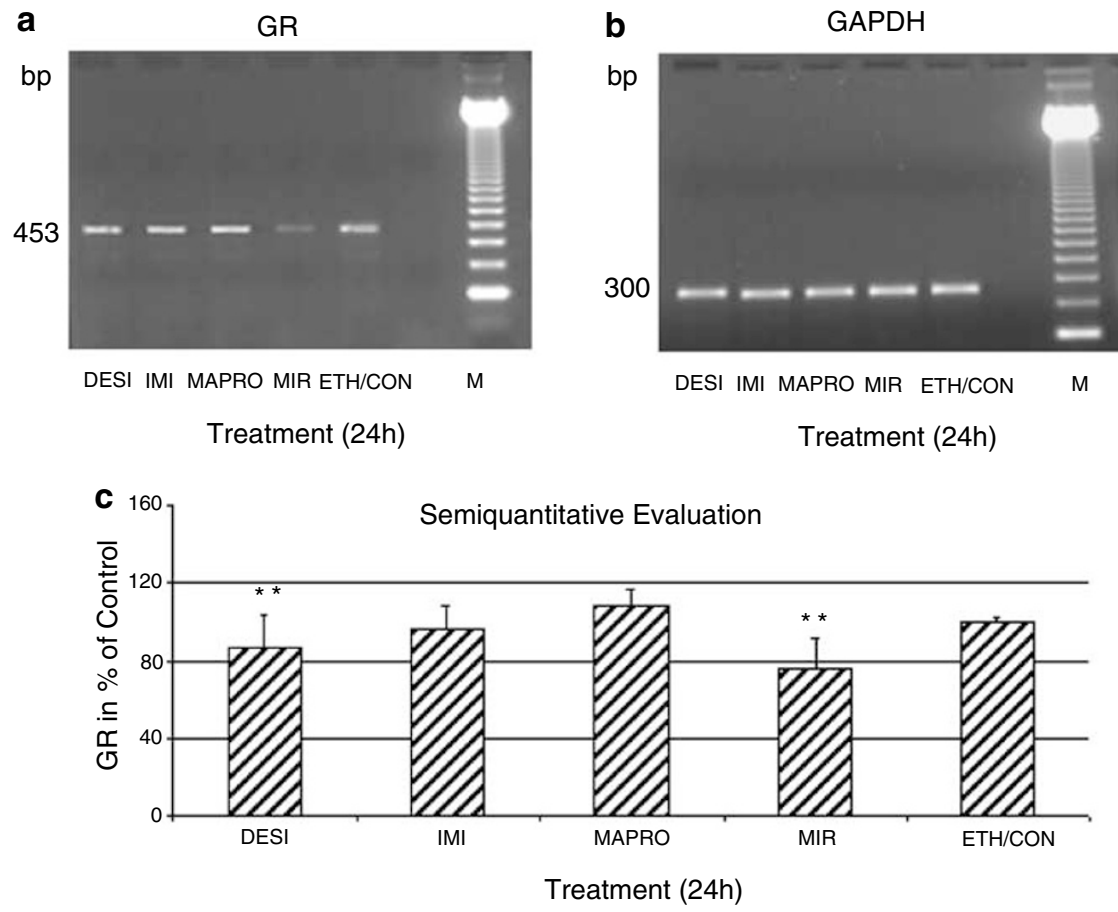

Figure I Effects of different ADs $\left(10^{-7} \mathrm{M}\right.$ ) on (a) GR and (b) GAPDH-mRNA levels in primary leukocytes after $24 \mathrm{~h}$ of treatment. The semiquantitative evaluation for GR-mRNA levels from II independent experiments is shown in (c) with a significant downregulation after DESI and MIR treatments (MannWhitney rank sum tests for $\mathrm{DESI}$ and $\mathrm{MIR}: \mathrm{p}=0.006)$ (DESI=desipramine; $\mid \mathrm{MI}=$ imipramine, $M A P R O=$ maprotiline, $M I R=$ mirtazapine, $E T H /$ $\mathrm{CON}=$ ethanol control). 
$10^{-7} \mathrm{M}$ of IMI and MAPRO induced only small effects on GR-mRNA levels $(96 \pm 12$ and $108 \pm 9 \%)$, whereas DESI and MIR significantly downregulated the GR-mRNA levels to $87 \pm 16$ and $76 \pm 16 \%$, respectively (Kruskal-Wallis oneway analysis of variance on ranks: $\mathrm{F}=7.882$, $\mathrm{df}=441.639$, $p<0.001$; Mann-Whitney rank sum tests for DESI and MIR: $p=0.006$ ) (Figures 1a, c). Control experiments showed that these treatments did not induce changes in GAPDH-mRNA levels (Figure 1b).

\section{Effects of ADs on GR-mRNA Levels in Monocytic U-937 Cells}

The effects of a $24 \mathrm{~h}$ treatment with DESI, IMI, MAPRO, and MIR on GR transcription in undifferentiated U-937 cells are shown in Figures $2 \mathrm{a}$ and c. A concentration of $10^{-7} \mathrm{M}$ of DESI and MIR significantly decreased the amounts of GRmRNA to $60 \pm 7$ and to $45 \pm 8 \%$ of the control levels after $24 \mathrm{~h}$ of treatment, respectively (Kruskal-Wallis one-way analysis of variances on ranks: $\mathrm{F}=13.477, \mathrm{df}=141.254$, $p \leqslant 0.001$; Student-Newman-Keuls tests for DESI $(p=0.002)$ and $\operatorname{MIR}(p=0.001))$, whereas IMI did not induce significant changes $(92 \pm 6 \%)(p>0.05)$. Treatment with MAPRO increased the GR-mRNA levels to $118 \pm 20 \%$ of control levels under these conditions, although not to a significant extent $(p>0.05)$ (Figures $2 \mathrm{a}, \mathrm{c})$. All treatments did not result in changes of GAPDH-mRNA levels (Figure 2b).

\section{Effects of Actinomycin D Treatment on the AD-Induced Changes in GR-mRNA Levels in U-937 Cells}

The nature of the transcriptional modulation of the $\mathrm{AD}$ induced changes was further examined in monocytic cells in the presence and in the absence of the RNA synthesis inhibitor Actinomycin D (Figure 3). The treatment with Actinomycin D effectively inhibited the biosynthesis of GRmRNA and GAPDH-mRNA: GR-mRNA levels were reduced to $24 \pm 5 \%$ (ETH), $22 \pm 4 \%$ (DESI), and $15 \pm 5 \%$ (IMI), resulting in an approximately four-fold decrease under treatment conditions with Actinomycin D. Interestingly, GR-mRNA levels after treatment with MAPRO were decreased approximately five-fold from $118 \pm 20$ to $23 \pm 4 \%$, with DESI approximately three-fold from $60 \pm 7$ to $22 \pm 4 \%$, and with MIR only about 0.3 -fold from $45 \pm 8$ to $31 \pm 4 \%$, suggesting differential effects of the ADs on GR-mRNA biosynthesis (Figure 3b, lanes 1-10, Figure 3c).

Regarding the GAPDH-mRNA levels, experiments with $\mathrm{ADs}$ and Actinomycin $\mathrm{D}$ revealed an approximately fourfold decrease without differential effects of ADs (Figure $3 \mathrm{~b}$, lanes 1-10, Figure 3c), suggesting a specificity of the effects of the ADs on GR-mRNA levels.

\section{Dose Dependence of the Effects of MIR on GR-mRNA Levels in Undifferentiated U-937 Cells}

Investigation of the dose dependence of the effects of MIR on GR-mRNA levels in U-937 cells was done with $10^{-5}$, $10^{-6}$, and $10^{-7} \mathrm{M}$ of MIR. Figure 4 demonstrates that the different concentrations induce a downregulation of GRmRNA levels in a dose-related manner after treatment for $24 \mathrm{~h}$. Data from the different concentrations $\left(10^{-5} \mathrm{M} \mathrm{ETH/}\right.$ CON: $174 \pm 46 \% ; 10^{-7}$ MIR: $129 \pm 23 \% ; 10^{-4}$ M ETH/CON: $111+14 \% ; 10^{-6}$ MIR: $92+15 \% ; 10^{-3} \mathrm{M}$ ETH/CON: $100 \pm 5 \% ; 10^{-5}$ MIR: $71 \pm 13 \%$ ) were normalized with regard to the $10^{-5} \mathrm{M}$ ETH/CON treatment (one-way analysis of variances on ranks: $\mathrm{F}=3.786, \mathrm{df}=173.097, p=0.027$ ).
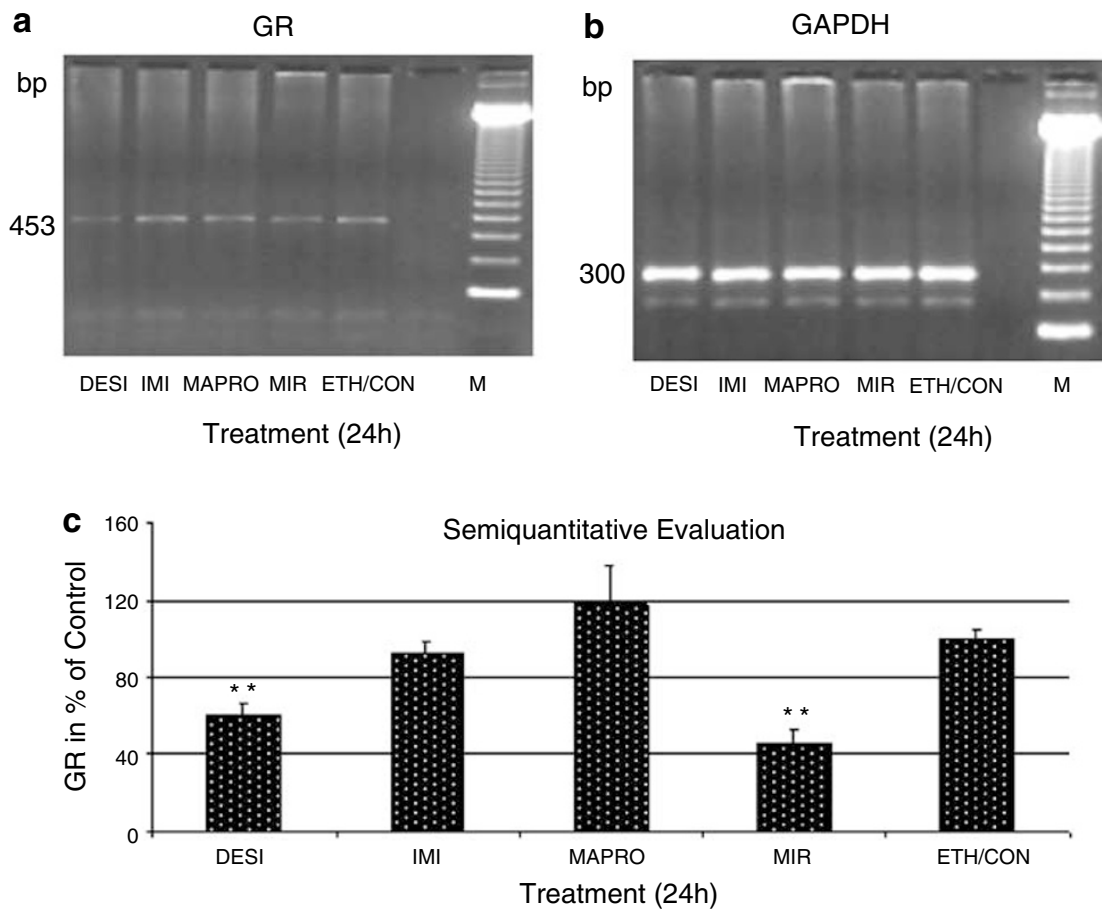

Figure 2 Effects of different ADs $\left(10^{-7} \mathrm{M}\right.$ ) on GR-mRNA levels in U-937 cells after treatment for $24 \mathrm{~h}$. The PCR data are shown for (a) GR and (b) GAPDH-mRNA levels. A semiquantitative evaluation for GR-mRNA from six independent experiments is shown in (c). Statistical evaluation of data revealed a significance of changes in GR-mRNA levels after treatment with DESI $(p=0.002)$ and MIR $(p=0.00$ I) Student-Newman-Keuls tests. 


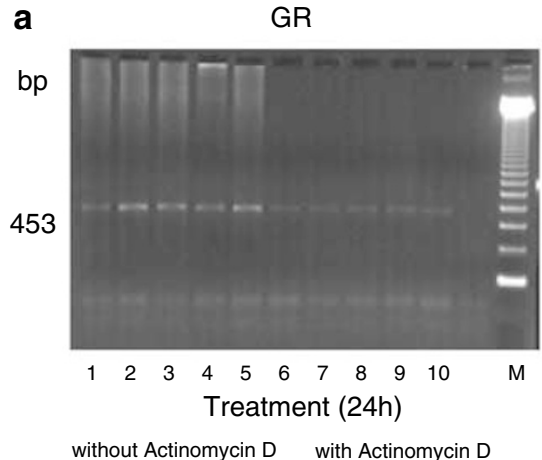

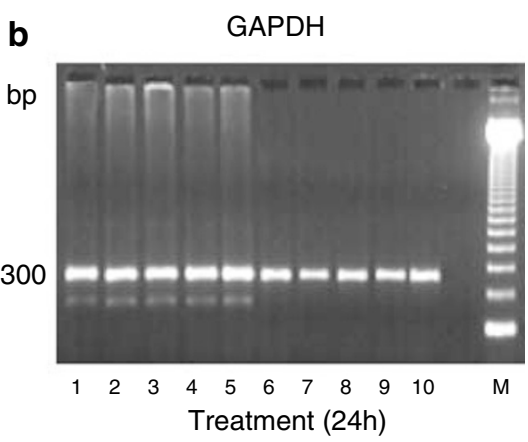

without Actinomycin D with Actinomycin D

Semiquantitative Evaluation

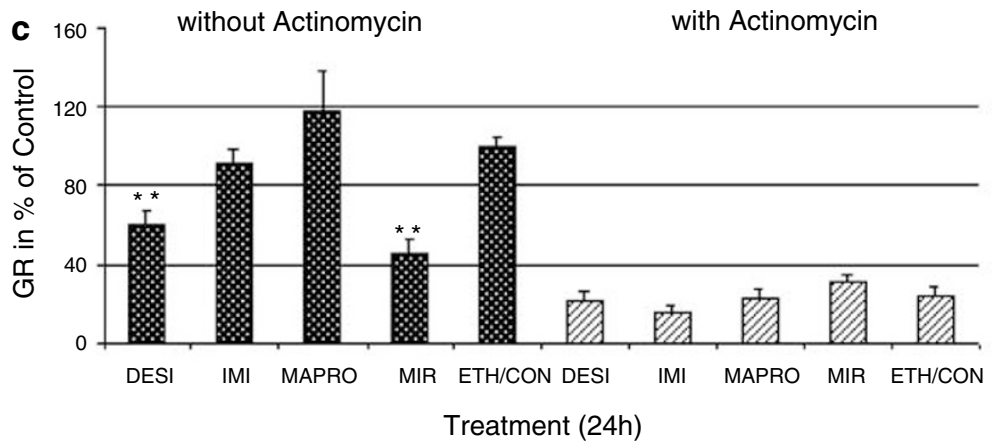

Figure 3 Actinomycin D induces a decrease in RNA amplification of GR- and GAPDH-mRNA levels after $24 \mathrm{~h}$ of treatment in U-937 cells (a (6-I0) and b (6-10)). A semiquantitative evaluation of Actinomycin D treatment compared to untreated $U-937$ cells is derived from three independent experiments and shown in (c). Statistical evaluation of data revealed a significant decrease of GR-mRNA levels after MIR and DESI treatment (Mann-Whitney rank sum tests for DESI and MIR: $p=0.006)(I-5: I=D E S I, 2=I M I, 3=M A P R O, 4=M I R, 5=E T H / C O N ; 6-I 0: I-5+$ Actinomycin $D$ at each treatment point).

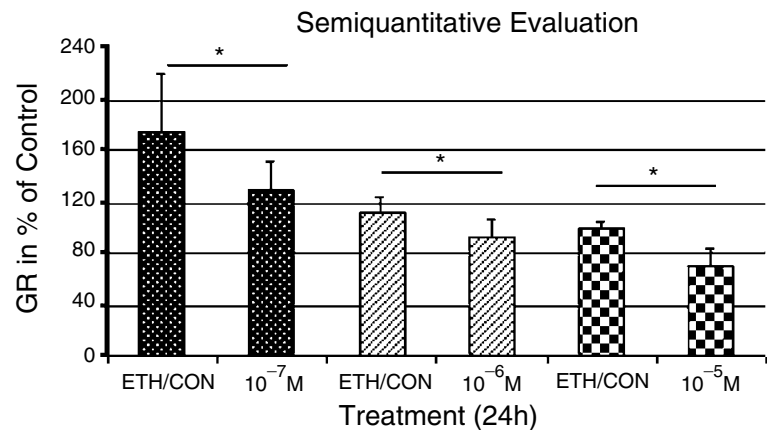

Figure 4 Dose-related effects of MIR and ETH on GR-mRNA levels after $24 \mathrm{~h}$ of treatment in undifferentiated U-937 cells. All three dosages of $\operatorname{MIR}\left(10^{-5}, 10^{-6}, 10^{-7} \mathrm{M}\right)$ and $\mathrm{ETH}\left(10^{-3}, 10^{-4}, 10^{-5} \mathrm{M}\right)$ affect GR-mRNA levels in U-937 cells. The maximal effect of MIR on the GR-mRNA was shown after a concentration of $10^{-7} \mathrm{M}$. A semiquantitative evaluation for GR-mRNA from three independent experiments is shown. Statistical evaluation of data revealed a significance of changes in GR-mRNA levels after treatment with MIR ( $p=0.027$ ) (Mann-Whitney rank sum tests).

The most pronounced effect of GR-mRNA downregulation was shown after $10^{-7} \mathrm{M}$ MIR treatment. Subsequently, this concentration was used for the additional experiments.

Time-Dependent Effects of MIR on GR-mRNA Levels in Undifferentiated and Differentiated U-937 Cells

Ragg et al (1998) induced U-937 cells to differentiate by a treatment with $40 \mathrm{nM}$ PMA. This treatment differentiates
U-937 cells to nondividing adherent monocytic cells. We obtained the same morphological changes after treatment with only $10 \mathrm{nM}$ PMA. The morphology of the undifferentiated and differentiated U-937 cells is shown in Figures $5 \mathrm{a}$ and $\mathrm{b}$.

MIR-induced changes in GR-mRNA levels were further characterized after treatment of U-937 cells in a timedependent manner. Data suggest that a concentration of $10^{-7} \mathrm{M}$ MIR exerts differential time-dependent effects on GR-mRNA levels with an initial upregulation from $103 \pm 10$ to $129 \pm 44 \%$ after $2.5 \mathrm{~h}$ of treatment $(1 \mathrm{~h}: 100 \pm 4$ to $105 \pm 14 \%)$. A downregulation of GR-mRNA levels from $124 \pm 27$ to $85 \pm 14 \%$ after $4 \mathrm{~h}$, from $125 \pm 32$ to $98 \pm 21 \%$ after $24 \mathrm{~h}$, and from $120 \pm 6$ to $83 \pm 14 \%$ after $48 \mathrm{~h}$ was detectable (Figures $5 \mathrm{c}$, e).

Because PMA induced a differentiation of the morphology of U-937 cells, we also investigated the possible changes of GR-mRNA levels after simultaneous treatment with PMA and MIR.

PCR and the densitometric quantification data are shown after PMA-induced differentiation in Figures $5 \mathrm{~d}$ and $\mathrm{f}$. The results indicate small effects of MIR with downregulation of GR-mRNA levels after $1 \mathrm{~h}$ from $100 \pm 4$ to $88 \pm 10 \%$ and a normalization after $48 \mathrm{~h}$ of treatment $(100 \pm 3$ to $105 \pm 5 \%)$ (Figures $5 \mathrm{~d}, \mathrm{f}$ ). After $2.5 \mathrm{~h}$ of MIR treatment, an upregulation of GR-mRNA from $105 \pm 3$ to $119 \pm 8 \%$ occurred, whereas after 4 and $24 \mathrm{~h}$ of treatment only marginal changes were detectable from $109 \pm 4$ to $100 \pm 5 \%$ and from $109 \pm 4$ to $95 \pm 9 \%$. Overall, the induced changes in the amounts of GR-mRNA did not reach the significance level 
a

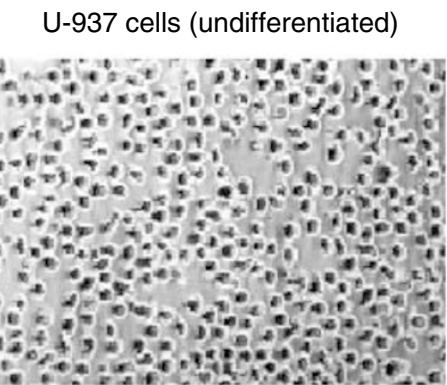

C

GR
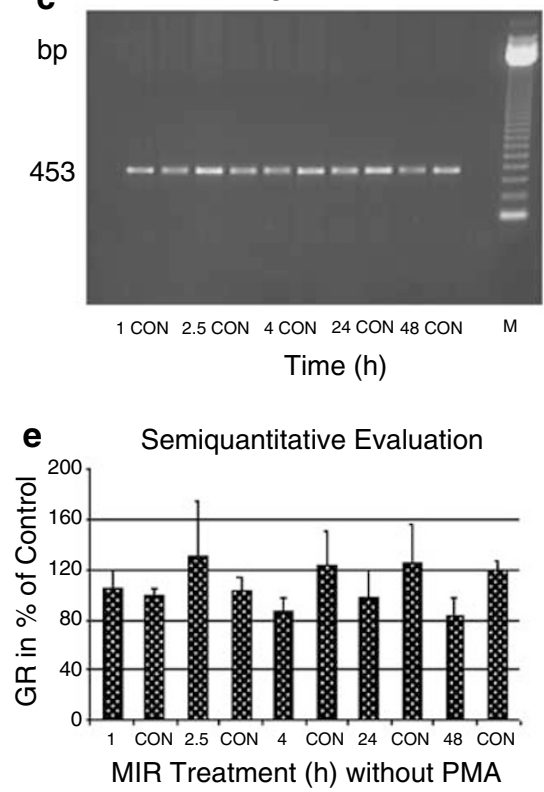

b U-937 cells (differentiated)
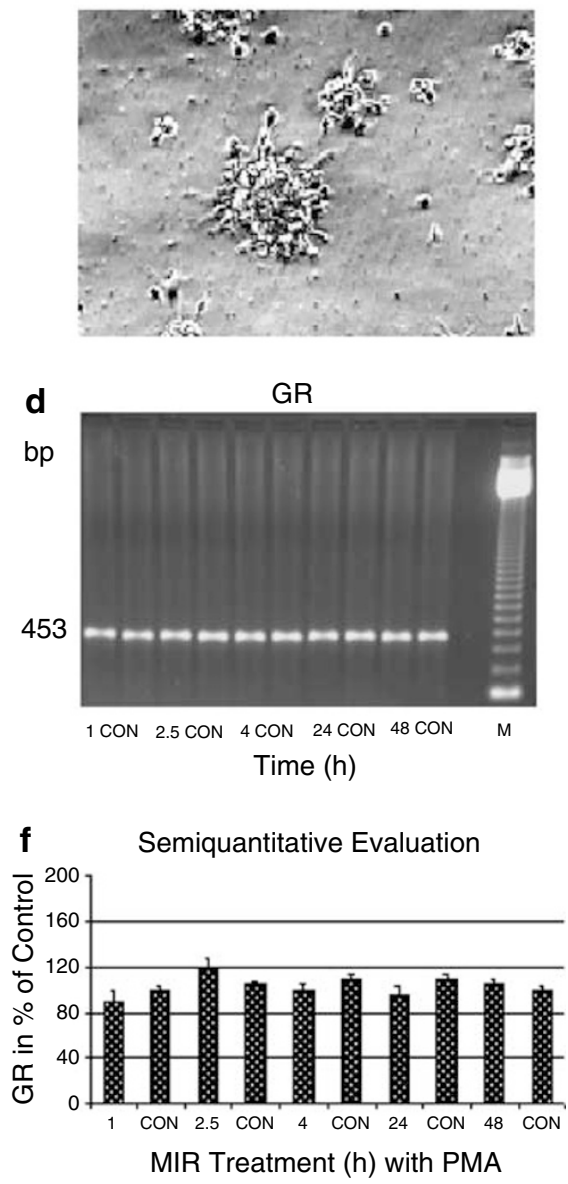

Figure 5 Time-related effects of MIR on GR-mRNA in undifferentiated and differentiated U-937 cells. Morphology of undifferentiated and differentiated U-937 cells is shown in (a) and (b). For differentiation, the cells were cultured for $72 \mathrm{~h}$ after the addition of I 0 nM PMA. Undifferentiated U-937 cells: The PCR amplification data (c) and semiquantitative analysis of PCR data (e) from three independent experiments show the effects of MIR in undifferentiated U-937 cells after different treatment periods (I, 2.5, 4, 24, and $48 \mathrm{~h}$ ) in comparison to the respective solvent-treated control. Differentiated U-937 cells: The PCR amplification data (d) and semiquantitative analysis of PCR data ( $f$ from three independent experiments demonstrate the effects of MIR in differentiated $U$ 937 cells after different treatment peroids (I, 2.5, 4, 24, and $48 \mathrm{~h}$ ) in comparison to the respective solvent-treated control.

and were markedly less pronounced in differentiated cells (Figures 5d, f) if compared to the undifferentiated conditions (Figures $4 \mathrm{c}, \mathrm{e}$ ).

\section{Effects of MIR and MIR/DEX on GR Protein Expression in U-937 Cells}

To examine the differential effects of MIR and MIR/DEX on GR protein expression, we used the fluorescence/immunostaining method in differentiated U-937 cells.

Since basal expression and translocation of GRs are regulated by glucocorticoids and an interaction between ADs and glucocorticoids is likely, effects were also examined under additional treatment with the glucocorticoid DEX. Cells were treated with $10^{-6} \mathrm{M}$ MIR or with $10^{-6} \mathrm{M}$ of both MIR and DEX, and the effects on GR expression were examined in a time-dependent manner after $1,2.5,4,24$, and $48 \mathrm{~h}$. Initially, the pattern of staining was heterogeneous among the cells with a diffuse fluorescence in both the cytoplasm and the nucleus. In most of the cells, the fluorescence was more intense in the cytoplasm than in the nucleus, and a continuous increase of GR protein was detectable between 4 and $48 \mathrm{~h}$ of MIR treatment (Figures 6g, i, k). The simultaneous treatment with MIR and DEX enhanced the GR protein expression after 1 and $2.5 \mathrm{~h}$ if compared to the MIR treatment alone (Figures 6d, f). After $48 \mathrm{~h}$ of MIR (MIR/DEX) treatment, GR levels were significantly increased to $119 \pm 11 \%(139 \pm 9 \%)$ in the cytoplasm and to $231 \pm 23 \%(231 \pm 25 \%)$ in the nucleus (Figure 7). Cells grown under AD- and DEX-free conditions showed a weak cytoplasmatic GR expression for all time points (demonstrated in the figures only for the $48 \mathrm{~h}$ treatment point), whereas the GR protein was not or only barely detectable in the nucleus under both ETH treatment conditions (Figures 6a, b).

\section{Effects of MIR and MIR/DEX Treatment on the GR Translocation in U-937 Cells}

For a better characterization of the GR translocation in U937 cells after MIR and MIR/DEX treatment, we chose the time points of 1 and $48 \mathrm{~h}$. After $1 \mathrm{~h}$ of treatment with both 

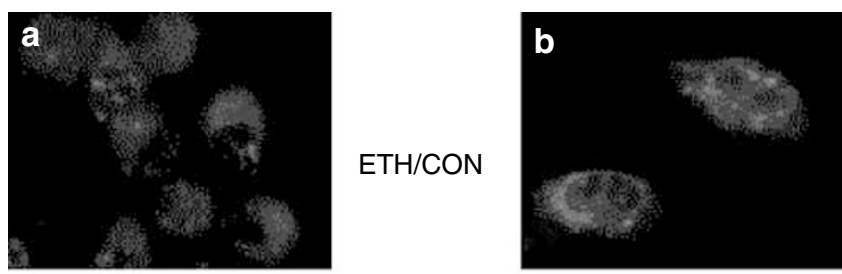

MIR

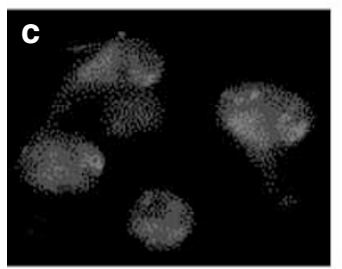

$1 \mathrm{~h}$
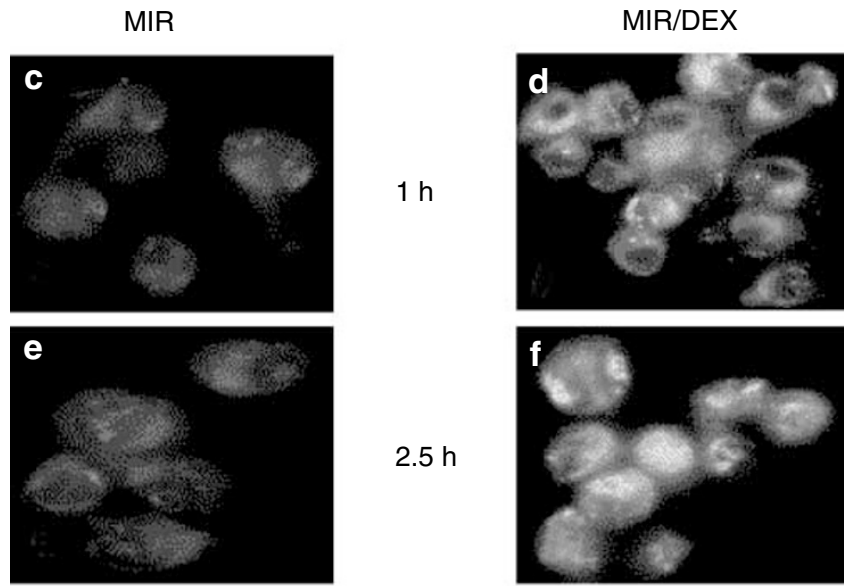

$2.5 \mathrm{~h}$
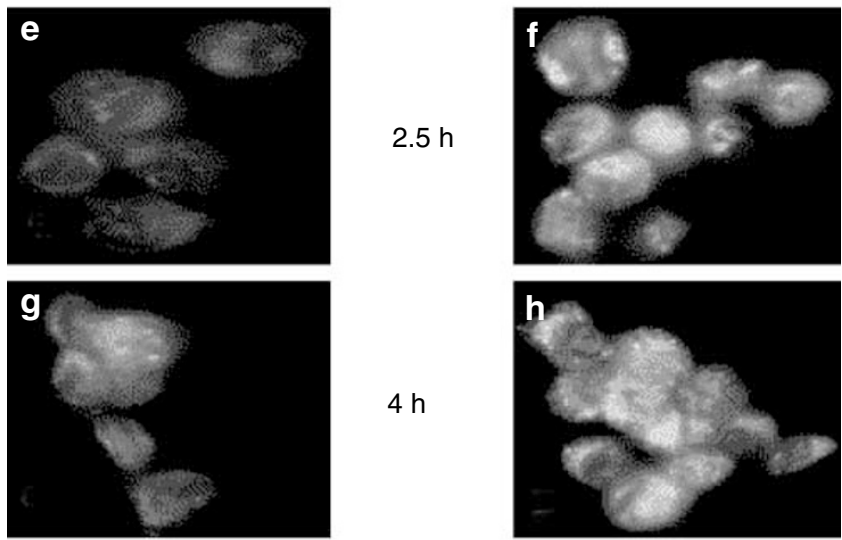

$4 \mathrm{~h}$
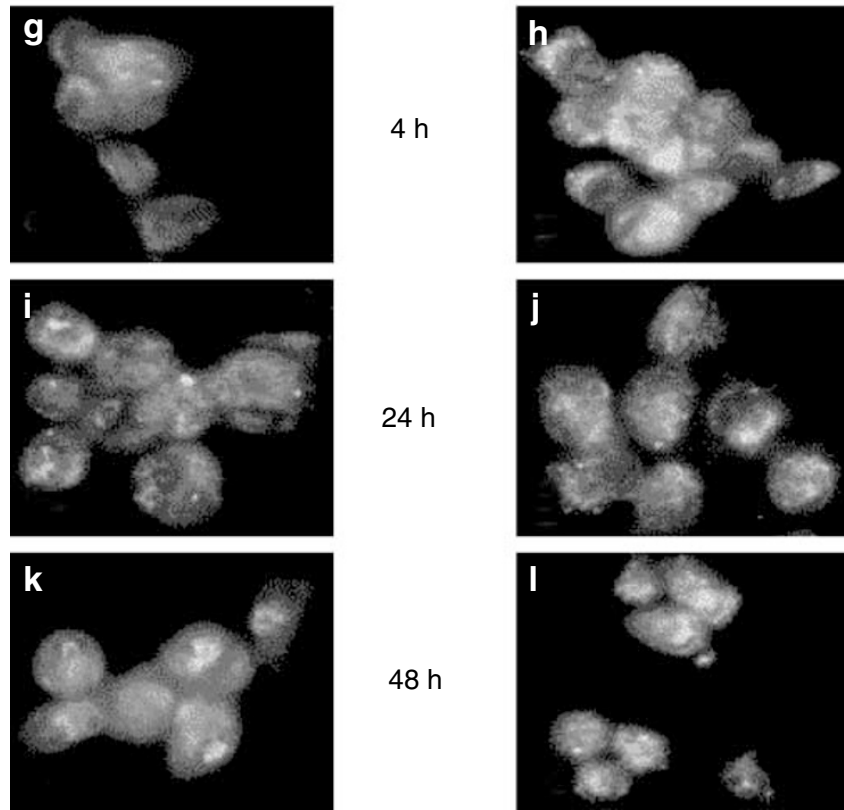

7b) led to a more intense staining in the cytoplasm if compared to MIR treatment alone (Figure 7a). After $48 \mathrm{~h}$ of treatment, a translocation of the GR protein from the cytoplasm to the nucleus with increased levels of GR protein in the nucleus was detectable in at least $50 \%$ of cells under both conditions (MIR and MIR/DEX) (Figures 7c, d).

Quantitative analysis of fluorescence was performed in blindly selected regions of the cytoplasm and nucleus by densitometric evaluation with the Gelscan 4.0 Professional Program. The results were standardized with regard to the levels of GR immunoreactivity in the cytoplasm (MIR, $1 \mathrm{~h}$ time point) and reached $100 \pm 10 \%$ in this cellular compartment and $81 \pm 12 \%$ in the nucleus (Figures 7a, e). After $48 \mathrm{~h}$ of MIR treatment, GR levels were significantly increased to $119 \pm 11 \%$ in the cytoplasm and to $231 \pm 23 \%$ in the nucleus (Figures 7c, e). Evaluation of data using the Kruskal-Wallis one-way analysis of variance on ranks showed a significance of the treatment $(H=29.151, \mathrm{df}=7$, $p<0.001)$.

Statistical analysis of data in the cytoplasm (a) and the nucleus (b) after $1 \mathrm{~h}$ of MIR treatment showed significant changes in comparison to the data of the cytoplasm and the nucleus after $48 \mathrm{~h}$ MIR treatment $(\mathrm{a}):(p=0.008, p \leqslant 0.001)$, (b): $(p=0.002, p \leqslant 0.001)$.

Similar effects were detectable for a concomitant treatment with MIR and DEX resulting in increased GR protein levels after $1 \mathrm{~h}$ of treatment in the cytoplasm $(122 \pm 8 \%)$ and a decrease in the nucleus (79 $\pm 7 \%$ (Figures $7 \mathrm{~b}, \mathrm{e}$ ). After $48 \mathrm{~h}$ of MIR/DEX treatment, the GR protein levels in the cytoplasm were increased to $139 \pm 9 \%$ and to $231 \pm 25 \%$ in the nucleus (Figures $7 d, e$ ).

Statistical comparison of data from the cytoplasm (a) and the nucleus (b) after $1 \mathrm{~h}$ MIR/DEX treatment with data from the cytoplasm and the nucleus after $48 \mathrm{~h}$ MIR/DEX treatment also showed a significance of treatments: (a) $(p=0.02, p \leqslant 0.001)$; (b) $(p \leqslant 0.05, p \leqslant 0.001)$.

\section{DISCUSSION}

Despite the increasing evidence that supports the assumption of a disturbed GR function in depressive patients (Holsboer, 1995, 2000; Modell et al, 1997; Pariante and Miller, 2001), only a few studies, including our own (Vedder et al, 1999), exist that conclusively point to direct effects of $\mathrm{ADs}$ on the regulation of GR-mRNA levels in the human system.

Therefore, we have extended our initial approach to further support the hypothesis of a modulation of GRmRNA levels by ADs in human blood cells. In our previous study, we have shown that both AMI (a classical tricyclic $\mathrm{AD}$ ) and DEX (a synthetic glucocorticoid with antidepressive actions) (Arana et al, 1995) increase the GR-mRNA levels in human primary leukocytes (Vedder et al, 1999). In the present study, we chose ADs with different pharmacological properties such as DESI, IMI, MAPRO, and MIR, an $\mathrm{AD}$ with a distinct mechanism of combined noradrenergic and serotonergic effects to characterize their actions on human primary leukocytes and on the U-937 monocytic cell line in more detail.

Our data show that in contrast to MAPRO and IMI, the ADs DESI and MIR significantly decrease GR-mRNA
MIR and MIR/DEX, the cytoplasm was more intensely stained than the nucleus (Figures 7a, b). Moreover, treatment with the combination of MIR and DEX (Figure 
MIR
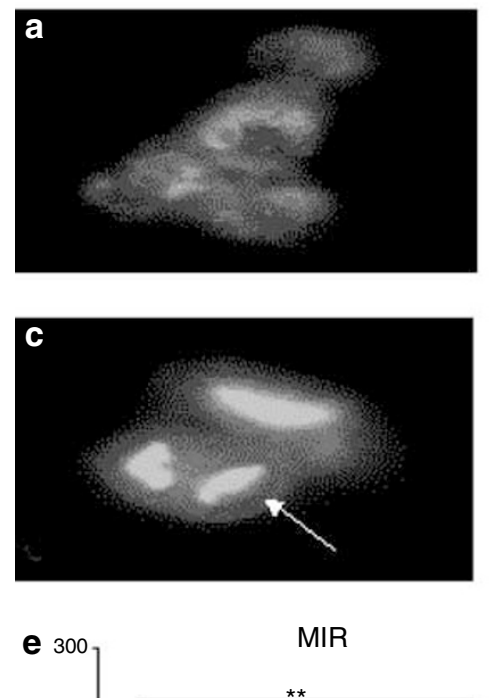

$1 \mathrm{~h}$

\section{MIR/DEX}
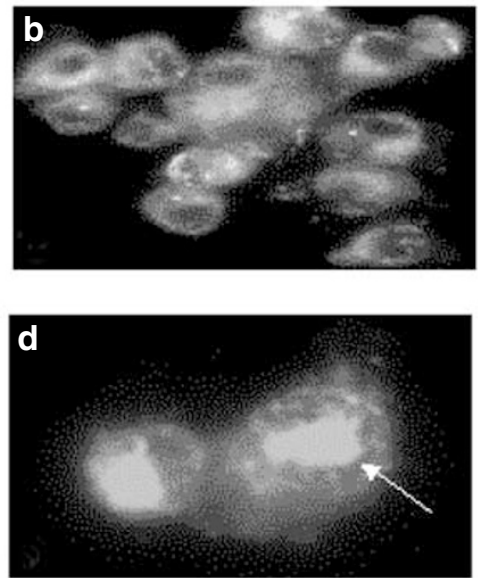

MIR/DEX

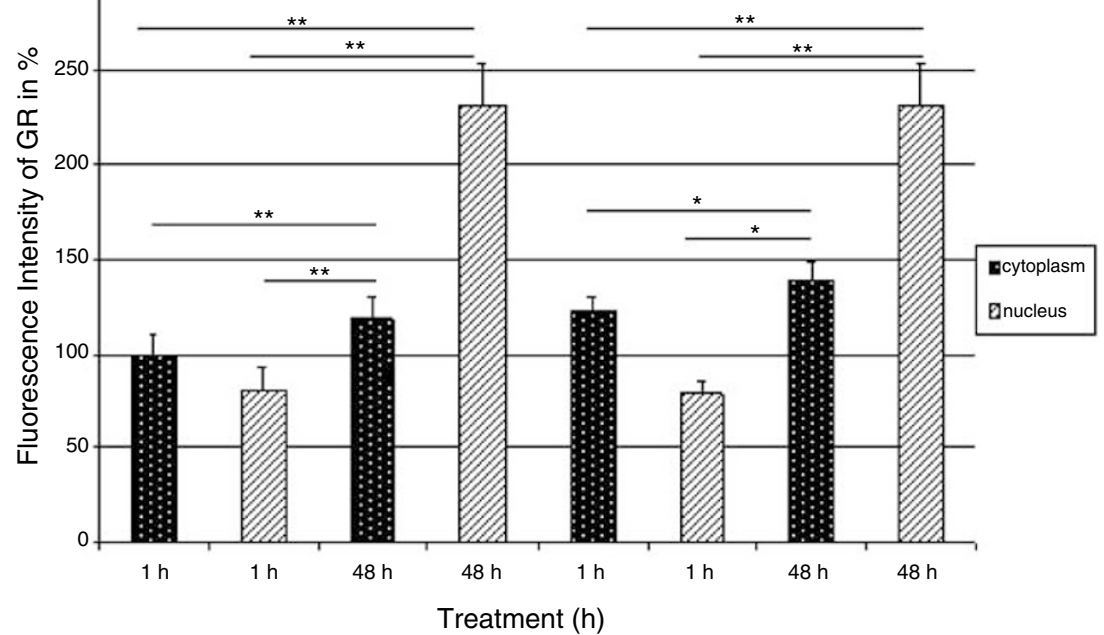

Figure 7 GR protein expression and translocation after MIR and simultaneous MIR and DEX treatment in U-937 cells. After treatment with MIR and MIR DEX for I h, the cytoplasm was more intensely stained than the nucleus $(a, b)$. After $48 \mathrm{~h}$ of treatment with MIR and MIR/DEX, a distinct translocation of GR protein from the cytoplasm to the nucleus was found in the cells (c, d). Quantitative analysis of fluorescence from the cytoplasm and nucleus is demonstrated in (e). Statistical evaluation of data revealed a significance of changes in GR protein between the cytoplasm and the nucleus (Mann-Whitney rank sum test: $* p \leqslant 0.05, * * \leqslant 0.01)(e)$.

levels after $24 \mathrm{~h}$ of incubation in both models. Our data of a downregulation of GR-mRNA after DESI treatment are not in line with the data of Pariante et al (1997). Only the short-term treatment $(2.5 \mathrm{~h})$ with MIR leads to an increase in GR-mRNA levels in undifferentiated U-937 cells, whereas a decrease was detectable after 4,24 , and $48 \mathrm{~h}$ of treatment. Such a time dependence of the effects of $\mathrm{AD}$ on GR-mRNA levels has also been described under in vivo conditions supporting the assumption that the time factor is indeed relevant for the changes induced (Reul et al, 1994).

Thus, the general effects of ADs on the GRs are detectable in an important cell population of the immune system, which has not only been shown to display alterations in depression (Maes, 1995; Seidel et al, 1996; Lanquillon et al, 2000; Rothermundt et al, 2001) but has also been demonstrated to be strongly connected to the psychopathological state (Maes et al, 1999; Rothermundt et al, 2001) and to the activation of the HPA system in depression, possibly caused in part or completely by proinflammatory cytokines like IL-1 and IL-6 (Maes et al, 1993a,b; Lanquillon et al, 2000). Moreover, the direct actions of ADs on immune functions such as the cytokine production (Xia et al, 1996) may be crucially involved in the treatment response to ADs (Lanquillon et al, 2000). With regard to our results, such effects may be caused via the AD actions on the GR-mRNA and on GR-mediated functions in immune cells and probably even specifically leukocytes. The dose-response relationship for the effects of MIR and the studies on the primary human leukocytes further support the relevance of the data. The dosages of MIR and of the other ADs used in our experiments are within the range of clinically relevant concentrations (Dodd et $a l, 2000$ ), and the effects on the primary human leukocytes further validate the results on the monocytic cell line U-937. 
Our experiments with Actinomycin D indicate that the regulatory influences of the $\mathrm{ADs}$ may be mediated via differential effects of the substances on the biosynthesis of the mRNA rather than other mechanisms such as effects on the stability of the mRNA. DESI and MIR induced a decrease in GR-mRNA levels compared with the other ADs, suggesting a specific effect on the GR, especially if considered in contrast to the GAPDH-mRNA levels.

In addition, our 'control data' on the dose-response and on the time course of the effects of MIR suggest a separate effect of ETH on GR-mRNA levels. The incubation with increasing concentrations of ETH results in a decrease of GR-RNA levels under our conditions. Such a decrease would be in line with very recent data from the literature showing that acute treatment of human mononuclear cells - similar to the cells used in this study - results in an increase in nuclear GRs and a reduced GR binding to the glucocorticoid response elements (GRE) (Szabo and Mandrekar, 2002). We here show that ETH increases GR-mRNA levels in a dose-dependent manner in our system. Moreover, the studies on the time course of the effects of ETH suggest that the effect occurs firstly after $4 \mathrm{~h}$ and is stable up to $48 \mathrm{~h}$ in undifferentiated U-937 cells. Other studies revealed that ETH also affected GRE binding under in vivo conditions in the rat brain, and that mianserin, another $A D$, interacts with the effects of ETH on the GR system (Roy et $a l, 2002)$. In conjunction with these data, we suggest that the effects of MIR - and also other ADs in our system such as DESI - may result, to a certain extent, from an interaction with the effects of ETH.

In addition to the basic data on the regulation on GRmRNA levels, we examined functional changes of the GR protein in monocytic U-937 cells by an immunohistochemical approach. These experiments revealed that MIR induced the expression of the GR protein and its translocation from the cytoplasm to the nucleus. This represents one of the most important steps in the initiation of the GR-mediated genomic responses (Beato et al, 1987, Beato and Klug, 2000) and has been shown for ADs in other systems such as fibroblastic cells (Pepin et al, 1992). This study, performed on mouse fibroblasts (LTK cell line) indicated that DESI stimulates the promoter activity of the GR gene after $24 \mathrm{~h}$ of treatment and leads to an increase in GR binding after $72 \mathrm{~h}$ of treatment. Based on these data, these authors conclude that DESI may directly stimulates the transcription of the GR gene. Pariante et al (1997), however, demonstrated that in the absence of steroids, DESI is able to induce a GR translocation without activation of GR-mediated gene transcription in L 929 cells. Additionally, the authors showed that treatment with DESI in the absence of steroids leads to an inhibition of GR gene transcription if compared to the effects in cells treated with DEX alone or after simultaneous application of DESI and DEX.

We extend these data to the human system and show that DESI and MIR downregulate the GR-mRNA levels in human primary leukocytes and in the undifferentiated monocytic cell line U-937. Although MIR downregulated the GR-mRNA after $4,24,48 \mathrm{~h}$ treatment in undifferentiated U-937 cells, in differentiated cells the GR-mRNA was hardly affected by the treatment at these time points. This result did not correspond to the increase of the GR protein after $4 \mathrm{~h}$ MIR treatment that was shown with immunostaining methods in differentiated U-937 cells and appear earlier (1h) by concomitant incubation with MIR and DEX. These findings of an upregulation of the GR protein after MIR and combined MIR and DEX treatment support the assumption that the effects of ADs are enhanced by glucocorticoids despite a downregulation of the mRNA levels after treatment with MIR in undifferentiated U-937 cells.

The effects of MIR to upregulate the GR-mRNA after short-time treatment $(2.5 \mathrm{~h})$ and to downregulate the GR-mRNA after long-time treatment (24-48 h) in undifferentiated cells are likely to be delayed on the basis of GR protein expression. We assume that the upregulation of the GR protein after $4-48 \mathrm{~h}$ treatment is followed by a downregulation of the GR protein at a later time. In this case, MIR might stabilize the GR protein half-life time. Additionally, we demonstrate a translocation of the GR protein after MIR and MIR/DEX treatment in a time-dependent manner. Our results show a translocation of the cytoplasmatic GR protein to the nucleus after treatment with MIR or with MIR/DEX. The treatment with the AD MIR alone and in the presence of the steroid DEX had no further effect on the staining of the cells or the nucleus. On the other hand, Pariante et al (1997) demonstrated an effect of brighter nuclei by concomitant DESI/ DEX treatment in comparison to a single treatment with DESI or DEX.

Under our conditions, the addition of DEX led to an enhancement of MIR effects with regard to the GR protein. If it is assumed that ADs need a basal concentration of GR activation by steroids for their effects, the actions of MIR might be mediated or at least influenced by basal steroids, present in the blood or in the media. Further addition of DEX would then lead to an additional - although rather slow-translocation of the GR protein to the nucleus. Regarding the effects of the AD and DEX on GR-mediated signal transduction, interactions with membrane steroid transporters such as the multidrug resistance p-glycoprotein have been shown as a potentially relevant mechanism of action (Pariante et al, 2001). It was hypothesized that this would lead to an increase in the intracellular concentrations of steroids and subsequently increase GR-induced gene transcription. Such a mechanism might not only explain the parallel effects of DEX and several ADs, but might also be an explanation for the rather slow effects of DEX under our conditions.

In summary, our data show differential effects of several ADs including the new AD MIR on GR-mRNA induction and effects of MIR on GR protein expression and functional parameters such as nuclear translocation. Although MIR upregulated the GR-mRNA at an early phase $(2.5 \mathrm{~h})$, it downregulated the GR-mRNA at a late phase (24-48 h); the GR protein was upregulated at an early phase $(4 \mathrm{~h})$, while the translocation of GR from the cytoplasm to the nucleus was induced at a late phase $(24-48 \mathrm{~h})$. Thereby, these data show both a downregulation of mRNA levels and a likely increase in GR-mediated signal transduction after treatment with the AD MIR. Overall, our data would support the hypothesis that ADs exert their therapeutical actions in the treatment of depressive disorders via their influence on GRs in the HPA-axis and in the immune system. 


\section{ABBREVIATIONS}

ADs, antidepressants; CNS, central nervous system; DESI, desipramine; DMEM, Dulbecco's modified Eagle's medium; DEX, dexamethasone; FITC, fluoresceine-isothiocyanate; GAPDH, glycerinaldehyde-3-phoshate dehydrogenase; GRs, glucocorticoid receptors; HPA, hypothalamic pituitary adrenocortical; IMI, imipramine; MAPRO, maprotiline; MDD, major depressive disorder; MIR, mirtazapine; NaSSA, noradrenergic and specific serotonergic antidepressant; PCR, polymerase chain reaction; PMA, phorbol 12 myristate-13 acetate; RNA, ribosomal nucleic acid; RT, reverse transcriptase.

\section{ACKNOWLEDGEMENTS}

This study was supported by the DFG (SFB 297/A6), the 'Bundesministerium für Bildung und Forschung' (01GSSO118; 01GS0168), and the Society for Neurobiological Research and Therapy. We thank Mrs S Fischer for the technical help with the experiments on the human blood cells.

\section{REFERENCES}

Arana GW, Santos AB, Laraia MT, McLeod-Bryant S, Beale MD, Rames LJ et al (1995). Dexamethasone for the treatment of depression: a randomized, placebo-controlled, double-blind trial. Am J Psychiatry 152: 265-267.

Arborelius L, Owens MJ, Plotsky PM, Nemeroff CB (1999). The role of corticotropin-releasing factor in depression and anxiety disorders. J Endocrinol 160: 1-12.

Barden N, Reul JM, Holsboer F (1995). Do antidepressants stabilize mood through actions on the hypothalamic-pituitary-adrenocortical system? Trends Neurosci 18: 6-11.

Beato M, Arnemann J, Chalapakis G, Slater E, Willmann T (1987). Gene regulation by steroid hormones. J Steroid Biochem 27: 9-14.

Beato M, Klug J (2000). Steroid hormone receptors: an update. Hum Reprod Update 6: 225-236.

Biagini G, Merlo Pich E, Carani C, Marrama P, Gustafsson JM, Fuxe $\mathrm{K}$ et al (1993). Indole-pyruvic acid, a tryptophan ketoanalogue, antagonizes the endocrine but not the behavioral effects of repeated stress in a model of depression. Biol Psychiatry 33: 712-719.

Brady LS, Whitfield Jr HJ, Fox RJ, Gold PW, Herkenham M (1991). Long-term antidepressant administration alters corticotropinreleasing hormone, tyrosine hydroxylase, and mineralocorticoid receptor gene expression in the rat brain. J Clin Invest 87: 831837.

Budziszewska B, Jaworska-Feil L, Kajta M, Lason W (2000). Antidepressant drugs inhibit glucocorticoid receptor-mediated gene transcription - a possible mechanism. Br J Pharmacol 130: 1385-1393.

Budziszewska B, Siwanowicz J, Przegalinski E (1994). The effect of chronic treatment with anti-depressant drugs on the corticosteroid receptor levels in the rat hippocampus. Pol J Pharmacol 46: 147-152.

Dodd S, Burrows GD, Norman TR (2000). Chiral determination of mirtazapine in human blood plasma by high-performance liquid chromatography. J Chromatogr B Biomed Sci Appl 748: 439-443.

Holsboer F (1995). Neuroendocrinology of mood disorders. In: Bloom FE, Kupfer DJ (eds). Psychopharmacology: The Fourth
Generation of Progress. Raven Press, Ltd.: New York. pp 957-969 Chapter 83.

Holsboer F (2000). The corticosteroid receptor hypothesis of depression. Neuropsychopharmacology 23: 477-501.

Lanquillon S, Krieg JC, Bening-Abu-Shach U, Vedder H (2000). Cytokine production and treatment response in major depressive disorder. Neuropsychopharmacology 22: 370-379.

Maes M (1995). Evidence for an immune response in major depression: a review and hypothesis. Prog Neuropsychopharmacol Biol Psychiatry 19: 11-38.

Maes M, Bosmans E, Meltzer HY, Scharpe S, Suy E (1993a). Interleukin-1 beta: a putative mediator of HPA axis hyperactivity in major depression? Am J Psychiatry 150: 1189-1193.

Maes M, Scharpe S, Meltzer HY, Bosmans E, Suy E, Calabrese J et al (1993b). Relationships between interleukin-6 activity, acute phase proteins, and function of the hypothalamic-pituitaryadrenal axis in severe depression. Psychiatry Res 49: 11-27.

Maes M, Smith R, Scharpe S (1995). The monocyte-T-lymphocyte hypothesis of major depression. Psychoneuroendocrinology 20: 111-116.

Maes M, Song C, Lin AH, Bonaccorso S, Kenis G, De Jongh R et al (1999). Negative immunoregulatory effects of antidepressants: inhibition of interferon-gamma and stimulation of interleukin10 secretion. Neuropsychopharmocology 20: 370-379.

Modell S, Yassouridis A, Huber J, Holsboer F (1997). Corticosteroid receptor function is decreased in depressed patients. Neuroendocrinology 65: 16-22.

Okugawa G, Omori K, Suzukawa J, Fujiseki Y, Kinoshita T, Inagaki C (1999). Long-term treatment with antidepressants increases glucocorticoid receptor binding and gene expression in cultured rat hippocampal neurones. J Neuroendocrinol 11: 887-895.

Pariante CM, Makoff A, Lovestone S, Feroli S, Heyden A, Miller AH et al (2001). Antidepressants enhance glucocorticoid receptor function in vitro by modulating the membrane steroid transporters. Br J Pharmacol 134: 1335-1343.

Pariante CM, Miller AH (2001). Glucocorticoid receptors in major depression: relevance to pathophysiology and treatment. Biol Psychiatry 49: 391-404.

Pariante CM, Nemeroff CB, Miller AH (1995). Glucocorticoid receptors in depression. Isr J Med Sci 31: 705-712.

Pariante CM, Pearce BD, Pisell TL, Owens MJ, Miller AH (1997). Steroid-independent translocation of the glucocorticoid receptor by the antidepressant desipramine. Mol Pharmacol 52: 571-581.

Peeters BW, Van Der Heijden R, Gubbels DG, Vanderheyden PML (1994). Effect of chronic antidepressant treatment on the hypothalamic-pituitary-adrenal axis of Wistar rats. Ann NY Acad Sci 746: 449-452.

Pepin MC, Beaulieu S, Barden N (1989). Antidepressants regulate glucocorticoid receptor messenger RNA concentrations in primary neural cultures. Mol Brain Res 6: 77-83.

Pepin MC, Govindan MV, Barden N (1992). Increased glucocorticoid receptor-gene promoter activity after antidepressant treatment. Mol Pharmacol 41: 1016-1022.

Przegalinski E, Budziszewska B (1993). The effect of long-term treatment with antidepressants drugs on the hippocampal mineralocorticoid and glucocorticoid receptors in rats. Neurosci Lett 161: 215-218.

Przegalinski E, Budziszewska B, Siwanowicz J, Jaworska L (1993). The effect of repeated combined treatment with nifedipine and antidepressant drugs or electroconvulsive shock on the hippocampal corticosteroid receptors in rats. Neuropharmacology 32: $1397-1400$

Ragg SJ, Kaga S, Berg KA, Ochi A (1998). The mitogen-activated protein kinase pathway inhibits ceramide-induced terminal differentiation of a human monoblastic leukemia cell line, U937. J Immunol 161: 1390-1398.

Reul JM, Labeur MS, Grigoriadis DE, De Souza EB, Holsboer F (1994). Hypothalamic-pituitary-adrenocortical axis change in 
the rat after long-term treatment with the reversible monoamine oxidase-A inhibitor moclobemide. Neuroendocrinology 60: 509519.

Reul JMHM, Stec I, Soder M, Holsboer F (1993). Chronic treatment of rats with the antidepressant amitryptyline attenuates the activity of the hypothalamic-pituitary-adrenocortical system. Endocrinology 133: 312-320.

Ribeiro SC, Tandon R, Grunhaus L, Greden JF (1993). The DST as a predictor of outcome in depression: a meta-analysis. $\mathrm{Am} \mathrm{J}$ Psychiatry 150: 1618-1629.

Rothermundt M, Arolt V, Peters M, Gutbrodt H, Fenker J, Kersting A et al (2001). Inflammatory markers in major depression and melancholia. J Affect Disord 63: 93-102.

Roy A, Mittal N, Zhang H, Pandey SC (2002). Modulation of cellular expression of glucocorticoid receptor and glucocorticoid response element-DNA binding in rat brain during alcohol drinking and withdrawal. J Pharmacol Exp Ther 301: 774-784.

Seckl JR, Fink G (1992). Antidepressants increase glucocorticoid and mineralocorticoid receptor mRNA expression in rat hippocampus in vivo. Neuroendocrinology 55: 621-626.
Antidepressants affect $\mathbf{G} R$ receptors in human monocytic cells A Heiske et al

Seidel A, Arolt V, Hunstiger M, Rink L, Behnisch A, Kirchner H (1996). Major depressive disorder is associated with elevated monocyte counts. Acta Psychiatr Scand 94: 198-204.

Szabo G, Mandrekar P (2002). Ethanol-mediated regulation of transcription factors in immunocompetent cells. Front Biosci 7: a80-a89.

Vedder H, Benning-Abu-Shach U, Lanquillon S, Krieg JC (1999). Regulation of glucocorticoid receptor-mRNA in human blood cells by amitriptyline and dexamethasone. J Psychiatr Res 33: 303-308.

Xia Z, De Pierre JW, Nassberger L (1996). Tricyclic antidepressants inhibit IL-6, IL- $1 \beta$ and TNF- $\alpha$ release in human blood monocytes and IL-2 and interferon- $\gamma$ in T cells. Immunopharmacology 34: 27-37.

Zobel AW, Yassouridis A, Frieboes RM, Holsboer F (1999). Prediction of medium-term outcome by cortisol response to the combined dexamethasone-CRH test in patients with remitted depression. Am J Psychiatry 156: 949-951. 